\title{
CRONOLOGIA DAS ALTERAÇÕES PÓS-MAGMÁTICAS ASSOCIADAS AO MACIÇO GRANITICOO DA SERRA BRANCA - GOIÁS
}

\section{CRISTINA PINTO-COELHO ${ }^{1} \&$ BERNARD CHAROY $^{2}$}

\begin{abstract}
CHRONOLOGY OF POST-MAGMATIC ALTERATIONS IN THE SERRA BRANCA GRANITE - GOIÁS STATE - BRAZIL CENTRAL The Serra Branca pluton, of medium Proterozoic age is situated in the Tocantins sub-province of the Tin Province of Goiás ; is composed by a several differenciatted granite types: a biotite-granite, predominant in the W part of the massif, a two-mica granite and a muscovite granite. A small topaz'granite is the most evolved type that outcrops in the Eastern part of the massif. The intense differentiation of the massif makes itself on an asymetrical manner due to the development of post-magmatic alteration processes that culminated with the formation of massive greisens. All rocks of the pluton (granite and greisens) together with the surrounding quartzites and quartz-micaschists of the Araí Groupe have been deformed and largelly recristallized during the Brasiliano tectono-metamorphic event. This deformation, as well as the intensity of the post-magmatic alterations, increases from W to E of the pluton. The relative importance of the hydrothermal alterations (s.l.) developed on the different types of the pluton manifests itself, chronologically, by located albitization, followed by greisenization and, by late microclinization that indiscriminately hits all the granitic and greisens types of the pluton. The main minerals of economical interest related to the greisenization episode are cassiterite, topaz and beryl. This alteration have strongly modified the original geochemical signatures of the granites. Chemical variations are mainly the expressions of those superimposed modifications.
\end{abstract}

Keywords: granite, hydrothermal alteration, albitization, greisenization, microclinization, Brazil

RESUMO O maciço granítico da Serra Branca (MGSB), de idade proterozóica média e situado na Província Estanífera de Goiás, é constituído por um conjunto de fácies formadas por biotita-granito, predominante na parte W do maciço, granito com duas micas e muscovita-granito. A fácies mais evoluída é representada por muscovita-topázio granito que aflora localizadamente na parte oriental do maciço. A intensa diferenciação do maciço faz-se de maneira assimétrica em virtude do desenvolvimento de processos de alteração pós-magmáticos que culminaram com a formação de greisenização de cúpula; a amplitude máxima desta greisenização é verificada na parte E do MGSB, onde se observam greisens maciços. Todo este conjunto litológico, assim como quartzitos e quartzo-micaxistos encaixantes do Grupo Araí, foi deformado e recristalizado durante o evento tectono-metamórfico do Ciclo Brasiliano. Esta deformação, bem como a intensidade das alterações pósmagmáticas, cresce de $\mathrm{W}$ para $\mathrm{E}$ do maciço. A importância relativa das alterações hidrotermais (s.l.) desenvolvidas nas diferentes fácies do maciço traduz-se, cronologicamente, por albitização localizada, seguida por greisenização e, finalmente, microclinização tardia que atinge, indiscriminadamente, todas as fácies graníticas e greisenizadas do maciço. Os principais minerais de interesse econômico relacionados ao episódio de greisenização são cassiterita, topázio e berilo.

Palavras-chave: granito, alteração hidrotermal, albitização, greisenização, microclinização, Goiás

\section{INTRODUÇÃO}

O Maciço granítico da Serra Branca (MGSB) situa-se na sub-província Tocantins da Província Estanífera de Goiás, segundo Marini \& Botelho (1986). O interesse econômico do maciço reside na cassiterita ligada aos greisens, descoberta em 1972, e ativamente explorada até o início da década de 80; a partir daí, com a queda do preco do estanho no mercado internacional, o interesse voltou-se para o berilo e as micas dos greisens, explorados de maneira artesanal, e logo abandonados. Os granitos da Província Estanífera, intrusivos no embasamento do Cinturão Dobrado Brasília, têm idades do Proterozóico médio e assemelham-se, quimicamente, aos granitos do tipo A (Marini \& Botelho 1986, Botelho 1992).

O MGSB forma uma estrutura elíptica, com eixo maior direcionado $\mathrm{N} 15^{\circ} \mathrm{W}$, dominada por quartzitos sub-horizontais do Grupo Araí, com idade proterozóica média, possivelmente posteriores à mise en place do plúton (Fig. 1). O maciço granítico encontra-se fortemente estruturado, adquirindo, na parte E, uma xistosidade plana tangencial sub-horizontal.

Quatro tipos de granitos foram aí identificados: a) biotita-granito porfiróide grosso, fortemente estruturado, com desenvolvimento de foliação inclinada para W, aflorando na porção ocidental do maciço, cuja mineralogia essencial está representada por quartzo, biotita, muscovita, feldspato potássico e albita. Feldspato potássico (microclínio) apresenta-se em três gerações de cristalização distintas: fenocristais com tendência subautomórfica, com blastese nos bordos e presença acentuada de inclusões fluidas, cristais subautomórficos a xenomórficos, comumente intersticiais, e com acentuado aspecto turvo, e uma terceira geração representada por indivíduos límpidos, desprovidos de quaisquer inclusões e restritos à matriz da rocha. O quartzo mostra-se, sobretudo, em agregados policristalinos, bem circunscritos e fortemente recristalizados. Plagioclásio apresenta, igualmente ao feldspato potássico, três gerações de cristalização: cristais subautomórficos a xenomórficos, pouco alongados, com maclas polissintéticas simples pouco deformadas, por vezes em fenocristais; contém, freqüentemente, abundantes inclusões de muscovita, fluorita, biotita e minerais argilosos. Não foi observado qualquer zoneamento químico entre as bordas e os núcleos destes minerais, cujas composições variaram sistematicamente entre $\mathrm{Ab}_{93} \mathrm{e} \mathrm{Ab}_{98}$ (dados obtidos em microssonda eletrônica e encontrados em Pinto-Coelho 1996). A se- gunda geração de plagioclásio está representada por indivíduos menores, igualmente subautomórficos a xenomórficos, geralmente límpidos e com poucas inclusões sólidas; sua composição química assemelhase à dos plagioclásios de primeira geração. Observa-se, por vezes, textura do tipo mirmequita. A terceira geração de plagioclásio é constituída pela geração de albita sob forma de exsoluções em feldspato potássico; b) granito porfiróide grosso com duas micas, com características petrográficas semelhantes às do biotita-granito porfiróide, exceto no que se refere aos aumentos da deformação, das proporções modais de quartzo, muscovita, fluorita, microclínio tardio e fases minerais acessórias radioativas e à terras raras, denotando, assim, maior desenvolvimento de processos de alteração pós-magmáticos (PintoCoelho et al. 1999). Ocorrem, nesta fácies, cristais reliquiares de granada almandina e de plagioclásio de composição mais básica $\left(\mathrm{An}_{20}\right.$ dados de microssonda eletrônica disponíveis em Pinto-Coelho, op. cit.); c) muscovita-granito heterogranular é a fácies mais evoluída do MGSB, aflora na porção oriental do maciço e sua mineralogia se resume a quartzo, albita, microclínio pertítico e muscovita, com as proporções modais desta última sendo nitidamente superiores às das demais fácies; d) muscovita-topázio granito é encontrado apenas localizadamente na porção oriental do maciço. Os minerais acessórios mais freqüentes nesta fácies são zircão, apatita, allanita, fluorita, monazita, óxidos/hidróxidos de ferro e opacos. Contato tectônico é observado entre o biotita-granito e o muscovita-granito.

Importantes variações observadas na composição modal dos granitos do MGSB resultam da atuação de fenômenos pós-magmáticos: albitização, greisenização - a mais desenvolvida - e microclinização. A greisenização oblitera inteiramente a textura da rocha original e é responsável pela formação de greisens maciços observados na porção oriental do MGSB. A composição mineralógica dos greisens é dominada pela associação quartzo-mica branca; topázio, fluorita, cassiterita, berilo, monazita, scheelita, grafita, esfalerita, zoisita, zircão, apatita, clorita, fenacita e opacos (sobretudo minerais de $\mathrm{Cu}$ e Fe) são minerais acessórios freqüentes.

Filões micáceos orientados $\mathrm{N}$ a N15-30 $\mathrm{W}$ associam-se, preferencialmente, ao muscovita-granito e aos greisens; compõem-se de $95 \%$ de micas com granulação fina à muita fina e coloração esverdeada característica. Minerais acessórios são quartzo, topázio, zircão, apatita, 


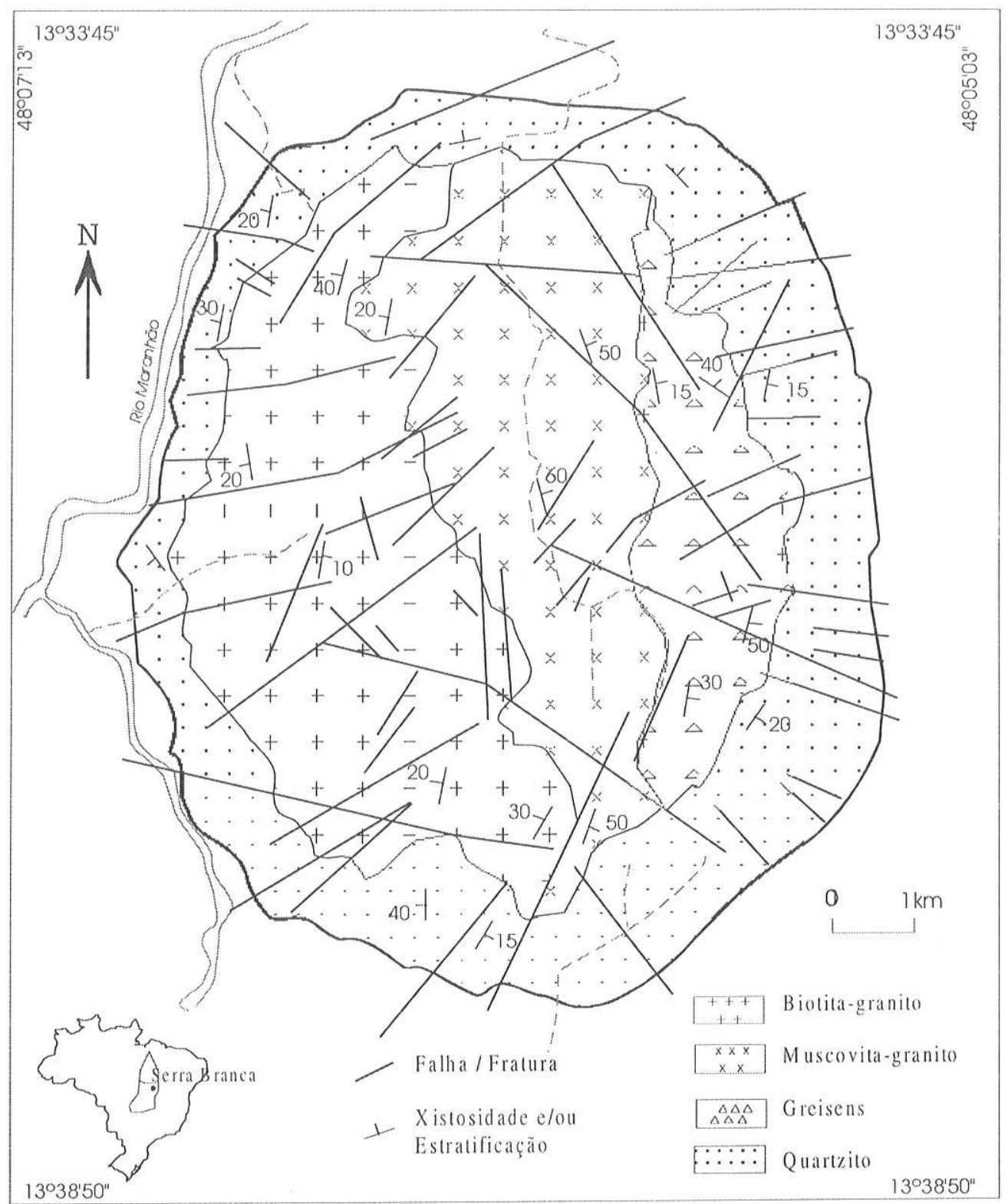

Figura I - Carta geológica esquemática do Macif̧o Granítico da Serra Branca e encaixantes (modificada de Andrade 1978)

opacos e, mais raramente, epidoto e fenacita. Estes fïlões, assim como os greisens, são afetados por foliação sub-horizontal ou levemente inclinada para $\mathrm{E}$.

Em nenhuma destas fácies foi identificada a presença de muscovita primária (magmática), conforme critérios texturais estabelecidos por Miller et al. (1981), Speer (1984), Bailey (1984) e Borodina \& Fershtater (1988). Independentemente do hábito, origem ou disposição textural, estas micas apresentam um caráter fengítico acentuado, sendo pobres em Mg, Ti, Na e Li (dados obtidos em microssonda eletrônica e disponíveis em Pinto-Coelho 1996). Não foram observadas variações importantes no comportamento de micas brancas de granitos, greisens ou mesmo filões micáceos.

Globalmente, os granitos do MGSB são silicosos, potássicos, fraca à moderadamente sódicos, pouco ferríferos, praticamente desprovidos de Ca, Mg e Ti e empobrecidos em F e Li (Fig. 1). As alterações pós-magmáticas modificaram a assinatura geoquímica original destas rochas, de maneira que as variações de composição químicomineralógicas observadas entre as diferentes fácies resultam destas modificações, preferencialmente a processos magmáticos (Pinto-Coelho 1996, Pinto-Coelho et al. 1999).

AS ALTERAÇÕES PÓS-MAGMÁTICAS

Os principais marcadores mineralógicos das alterações pós-magmáticas nas rochas do MGSB são albita, muscovita, fluorita e topázio. De acordo com
Tabela I - Teores médios em óxidos e parâmetros multicatiônicos das fácies graníticas e greisens do Maciço da Serra Branca. $n=$ número de amostras analisadas; $t r=$ traços; $n$. $a .=n a \tilde{o}$ analisado. Os valores relativos ao muscovita-topázio granito estão incluídos naqueles referentes ao muscovita-granito. $B T=$ biotita-granito; $G 2 M=$ granito com duas micas; $M G=$ muscovita granito; $G R=$ greisens

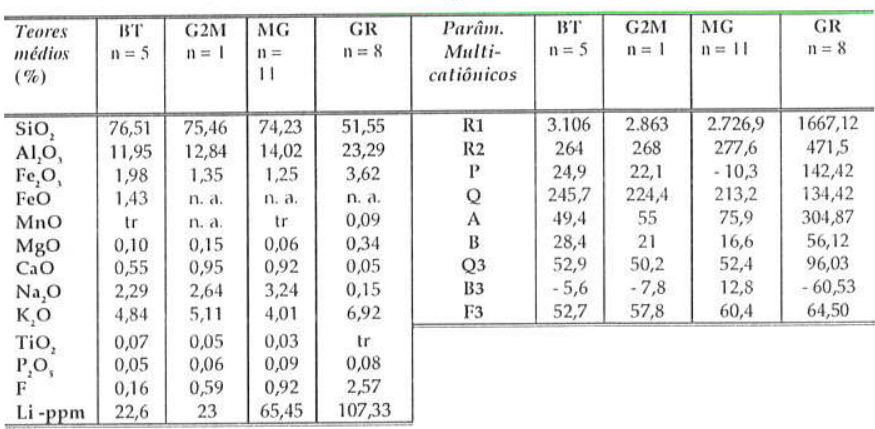

suas relações texturais, pode-se afirmar que estes minerais tiveram cristalização tardia, desenvolvendo-se às custas de minerais puramente magmáticos ou substituindo minerais pré-cristalizados. Estudos petrográficos mostraram que: a) as porcentagens modais de mica bran- 
ca aumentam global e paralelamente às do plagioclásio albítico e a importância destes dois minerais faz-se de maneira interdependente nas fácies graníticas; b) o topázio não mostra relação estreita com a albitização, uma vez que encontra-se ausente nos granitos mais enriquecidos em albita; c) as quantidades de fluorita tampouco são influenciadas pela cristalização da albita. Assim sendo, o registro dos fenômenos de alteração pós-magmáticos no MGSB é particularmente bem caracterizado, onde são observadas, em ordem cronológica, albitização, greisenização e microclinização.

Albitização A albitização é um processo pós-magmático que permanece relativamente discreto no MGSB, tendo sido observada apenas em algumas amostras de biotita-granito. Evidencia-se pela presença de albita do tipo chess-board, ou em vias de transformação em chessboard, nas bordas de fraturas que seccionam fenocristais de feldspato potássico pertítico (microclínio) (Fig. 2).

Manchas de albita, grosseiramente coalescentes, desenvolvem-se sobre o microclínio do muscovita-granito e poderiam corresponder a vestígios do fenômeno de albitização. Uma particularidade, observada unicamente no muscovita-granito é a presença de feldspato potássico, precocemente cristalizado e com mesma orientação óptica da albita hospedeira, contendo inúmeras inclusões fluidas (Fig. 3). Tal textura poderia, igualmente, corresponder a vestígios do processo de albitização. Não obstante, o fenômeno permanece global e espacialmente limitado. Albita do tipo chess-board não foi encontrada nas fácies greisenizadas, o que indicaria a anterioridade do processo de albitização com relação à greisenização.

Greisenização De maneira esquemática, a greisenização pode ser representada pelo fenômeno de hidrólise dos feldspatos, segundo reações incongruentes de dissolução (Stemprok 1987):

$3 \mathrm{NaAlSi}_{3} \mathrm{O}_{8}+2 \mathrm{H}^{+} \Rightarrow \mathrm{NaAl}_{2} \mathrm{AlSi}_{3} \mathrm{O}_{10}(\mathrm{OH})_{2}+6 \mathrm{SiO}_{2}+2 \mathrm{Na}^{+} \mathrm{aq}$
$3 \mathrm{KAlSi}_{3} \mathrm{O}_{8}+2 \mathrm{H}^{+} \Rightarrow \mathrm{KAl}_{2} \mathrm{AlSi}_{3} \mathrm{O}_{10}(\mathrm{OH})_{2}+6 \mathrm{SiO}_{2}+2 \mathrm{~K}^{+} \mathrm{aq}$

Os greisens associados ao MGSB têm associação mineralógica dominada por mica branca + quartzo. A mica branca de composição fengítica, de acordo com dados obtidos à microssonda eletrônica (Pinto-Coelho 1996), é heterogênea e cristaliza-se em várias gerações: placas deformadas que conferem xistosidade à rocha, ou ainda sob forma de agregados de finas palhetas imersas na mesóstase. É freqüente, ainda, em inclusões nas fases acessórias (topázio e fluorita), ou em pseudomorfose sobre um mineral não identificado, com forma retangular e incluso em cassiterita.

A cristalização tardia de parte da fengita pode ser identificada quando a mesma atua como "cimento" de outras fases minerais, como cassiterita, por exemplo.

Os feldspatos da rocha original raramente são conservados sob forma de relictos albíticos, e, quando isto pode ser observado, encontramse inclusos em quartzo e mostram composição idêntica à do plagioclásio do muscovita-granito $\left(\mathrm{Ab}_{98}-\mathrm{An}_{2}\right)$. Por outro lado, feldspato neoformado encontra-se presente em maior ou menor abundância. Topázio, fluorita, cassiterita, monazita, scheelita, grafita, esfalerita, zoisita, zircão, apatita, clorita, berilo, fenacita e opacos ( $\mathrm{Fe}$ e Cu) são comumente encontrados. A cassiterita acha-se disseminada, ou sob forma de agregados com coloração castanha.

A textura dos greisens é equi à heterogranular com granulação fina à média (2-7 mm), apresentando, freqüentemente, agregados quartzosos pluricentimétricos que poderiam corresponder a veios e exsudados. A estruturação dos greisens é intensamente marcada, com foliação sub-horizontal ou ligeiramente inclinada para Leste.

Microclinização tardia Contrariamente à albitização anteriormente descrita, o fenômeno de microclinização é onipresente no MGSB, atingindo fácies graníticas, greisenizadas e os filões micáceos. O microclínio desenvolvido durante esta fase de alteração pósmagmática é particularmente límpido, apresenta geminação em grade bem desenvolvida e encontra-se rigorosamente desprovido de qualquer exsolução albítica, inclusão mineral ou fluida. Nas fácies graníticas, este microclínio tardio desenvolve-se, preferencialmente, nas bordas do microclínio precoce, mas ocorre, ainda, associado à matriz dos granitos.

Nos greisens, as fases feldspáticas iniciais foram substituídas pelo microclínio tardio; observa-se aqui a presença de "olhos"

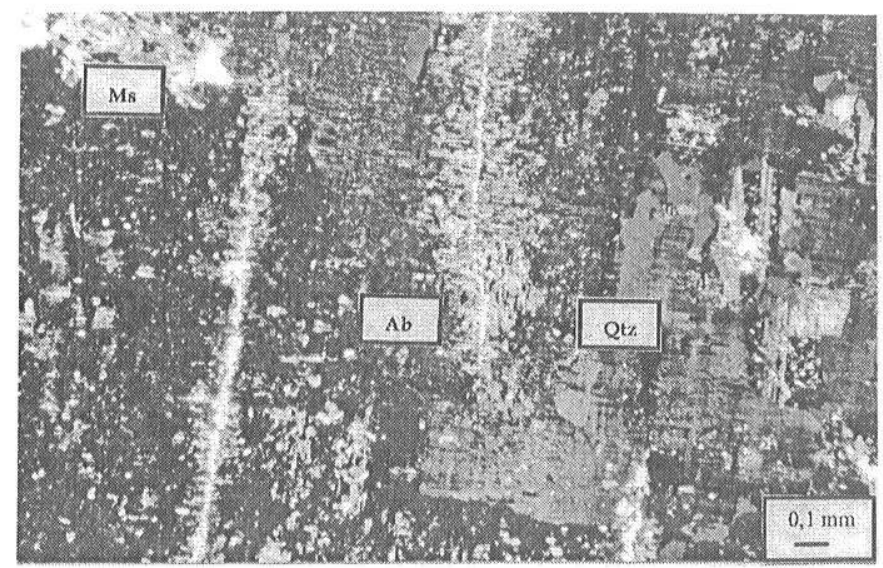

Figura 2 - Textura do tipo chess-board em biotita-granito, onde o feldspato potássico de primeira geração se transforma na periferia dos grãos e ao longo de fraturas. $M s=$ muscovita; $A b=$ albita; $Q t z=$ quartzo. NX

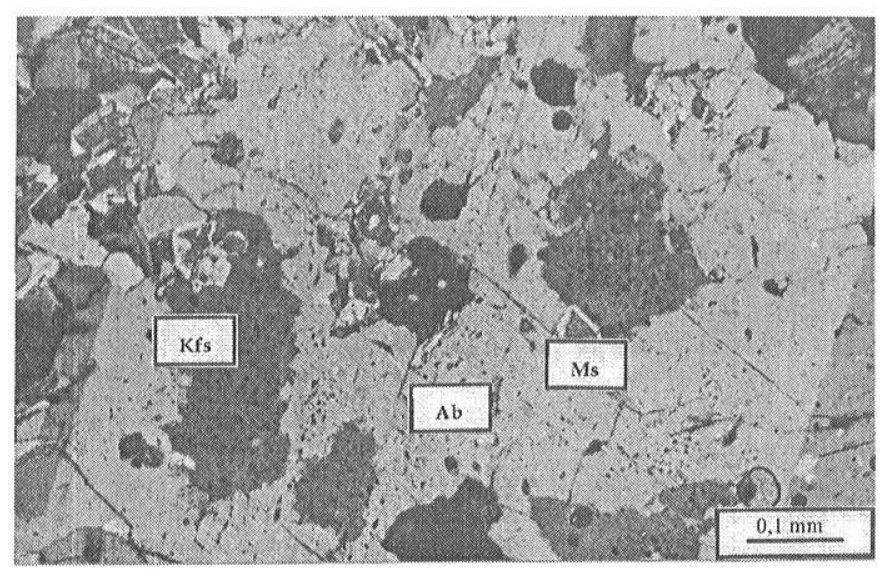

Figura 3 - Feldspato potássico (Kfs) de primeira geração, mostrando abundantes inclusões fluidas, em albita $(A b)$ do muscovita-granito. $N X$

xenomórficos de microclínio envoltos por indivíduos de mica branca. Tal textura, onde o microclínio acompanha a foliação marcada pela mica, demonstraria o caráter posterior do fenômeno de microclinização com relação à greisenização e, por outro lado, seu caráter aparentemente anterior com relação à deformação. Observa-se, freqüentemente, em amostras de greisens, o microclínio tardio cimentando fragmentos de cristais de cassiterita, demonstrando, assim, sua cronologia pósmineralização (Fig. 4).

Nos filões micáceos, o microclínio, comumente caulinizado, ocorre em pequenas manchas esbranquiçadas e pulverulentas associadas à matriz micácea. Igualmente aqui, este mineral acompanha a forte estruturação da rocha; sua posição temporária com relação à crenulação dos fílões micáceos não pôde ser estabelecida.

A composição do microclínio tardio, encontrado tanto em fácies graníticas, quanto em fácies greisenizadas e filões micáceos do MGSB, obtida em microssonda eletrônica, não difere daquela do microclínio magmático precoce, ou seja, Or ${ }_{46} \mathrm{Ab}_{4}$ (Pinto-Coelho 1996).

Outro estágio de cristalização associado às alterações pósmagmáticas do MGSB, observado, sobretudo, no biotita-granito, está representado pela formação de microclínio tardio, seguida de mica branca e quartzo, com presença local de fluorita e fases carbonáticas (Fig. 5).

DISCUSSÃO E CONCLUSÕES A importância relativa (em volume) das alterações pós-magmáticas desenvolvidas nas diferentes fácies do MGSB é extremamente variável: a albitização, unicamente representada, de maneira discreta, no biotita-granito, evidencia-se pelo desenvolvimento de albita do tipo chess-board. Entretanto, a extensão deste fenômeno pode ter sido maior ao se considerar a albita 
onipresente nestas rochas como o resultado de uma sodificação de um plagioclásio magmático mais cálcico. O plagioclásio das fácies graníticas, de natureza albítica, poderia corresponder, assim, à transformação de um plagioclásio mais cálcico, onde certos relictos foram encontrados no granito com duas micas. O Ca liberado e lixiviado pelo fluido hidrotermal poderia participar da precipitação da fluorita, estando o F disponível no sistema (Ferry 1979, Manning \& Exley 1984).

Outro indício favorável ao fenômeno de albitização de um plagioclásio precoce menos sódico seria a presença acentuada de inclusões de minerais argilosos em plagioclásio da primeira geração de cristalização (Manning \& Exley, op. cit.), comumente observada na fácies granítica à biotita.

Albita secundária com fácies chess-board é classicamente interpretada como resultado da substituição de feldspato potássico primário, via crescimento das pertitas em manchas (Smith 1974, Moore \& Liou 1979, Pascal 1979, Witt 1988, Charoy \& Pollard 1989). No MGSB, tal textura é claramente expressa pela albitização observada ao longo de fraturas que seccionam o feldspato potássico (Fig. 2); estas fraturas são, ainda, colmatadas por assembléia de quartzo + fengita, penecontemporânea ao fenômeno de albitização. Elementos terras raras são igualmente móveis, uma vez que foram aí observados fluoretos de TR (Pinto-Coelho 1996, Pinto-Coelho et al. 1999).

De acordo com Orville (1963), a albitização é caracterizada pela seguinte reação de troca:

$\mathrm{KAlSi}_{3} \mathrm{O}_{8}+\mathrm{Na}^{+} \Rightarrow \mathrm{NaAlSi}_{3} \mathrm{O}_{8}+\mathrm{K}^{+}$

De acordo com este autor, um fluido saturado em Cl é sistematicamente mais sódico que os feldspatos alcalinos em equilíbrio e torna-se mais sódico com a diminuição da temperatura, favorecendo, assim, a introdução de $\mathrm{K}$ no feldspato. A natureza do volátil também é importante: a razão $\mathrm{K} / \mathrm{Na}$ de dado fluido em equilíbrio com feldspato alcalino em dada temperatura é inferior em presença de F. A albitização pode, assim, ser conseqüência da mudança na natureza do halógeno volátil da fase fluida: diminuição do $\mathrm{F}$ ou aumento do $\mathrm{Cl}$ (Pichavant 1983, Pollard et al. 1987, Charoy \& Pollard 1989). Mudanças na natureza dos fluidos que circularam nas rochas do MGSB, sobretudo aqueles relacionados a processos tectônicos ligados ao episódios de deformação do Ciclo Brasiliano, foram evidenciadas durante estudos microtermométricos realizados em amostras destas rochas, onde variações extremas foram observadas, sobretudo em valores de salinidade global, em diversas populações de inclusões fluidas. Temperaturas eutéticas, ou temperaturas de fusão do gelo muito baixas, poderiam indicar a presença de outros cátions além de $\mathrm{Na}$, demonstrando, assim, a presença de um fluido com quimismo mais complexo do que o do sistema $\mathrm{NaCl}-\mathrm{H}_{2} \mathrm{O}$, usualmente considerado para o traçado de isócoras de fluidos aquosos ou aquo-carbônicos (Pinto-Coelho 1996).

Embora ocorra de mancira mais evidente na porção oriental do MGSB, a greisenização pode ser rastreada de maneira mais ou menos intensa através da presença indiscriminada de muscovita em proporções modais variáveis em todas as fácies graníticas. Do ponto de vista estritamente geoquímico, global e teórico, a greisenização é caracterizada pela hidrólise das fases feldspáticas do granito parental, o que traduz uma lixiviação maior da sílica, mas, sobretudo de $\mathrm{Na}_{0} \mathrm{O}$. As amostras de greisens associados ao MGSB analisadas geoquimicamente (Pinto-Coelho, op. cit.) mostram concentrações extremamente variáveis em $\mathrm{SiO}_{2}, \mathrm{Al}_{2} \mathrm{O}_{2}$ e $\mathrm{K}_{2} \mathrm{O}$, traduzindo, assim, variações importantes nas proporçốes modais das duas fases mineralógicas maiores, ou seja, quartzo e muscovita. Tais variações mostram que o comportamento agressivo dos fluidos hidrotermais é mutável e que as reações de hidrólise são complexas e numerosas. Não obstante, foi possível através da interpretação de diagramas usualmente empregados para tal fim, estabelecer um trend de filiação magmática biotita-granito $\Rightarrow$ granito com duas micas $\Rightarrow$ muscovita-granito $\Rightarrow$ greisens. No diagrama Q-P (Charoy 1979), mostrado na Figura 6, onde $Q=\mathrm{Si} / 3$ $(\mathrm{K}+\mathrm{Na}+2 \mathrm{Ca} / 3)$ e $\mathbf{P}=\mathbf{K}-(\mathrm{Na}+\mathrm{Ca})$, em proporções milicatiônicas, os greisens do MGSB deslocam-se paralelamente ao trend de distribuição dos greisens, ou seja, entre os pólos Q e musc, e passam por G, pólo teórico que define a hidrólise conjunta dos feldspatos. Nos diagramas propostos por La Roche (1980), e que consideram também parâmetros multicatiônicos, estes greisens plotam-se no domínio peraluminoso, entre os pólos da muscovita e quartzo (Fig. 7).

A quase totalidade dos elementos traços varia de maneira importan-

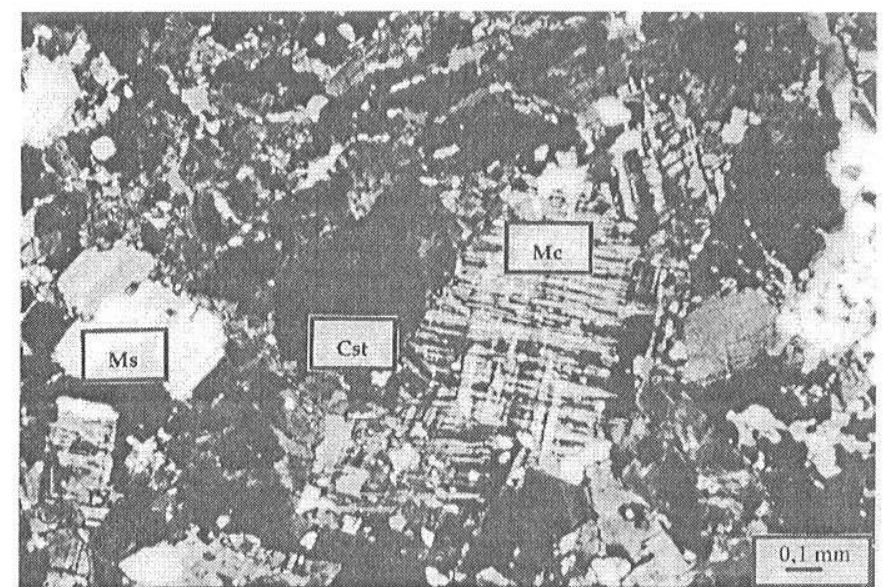

Figura 4 - Cristais de cassiterita (Cst) fraturados e cimentados por microclínio tardio (Mc) e muscovita (Ms). NX

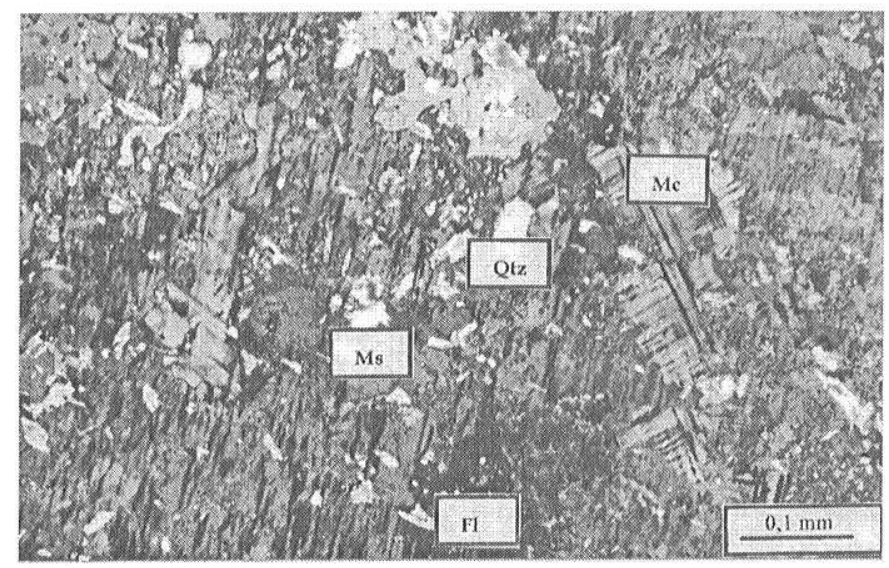

Figura 5 - Sequiência de alteração pós-magmática representada pela formação de microclínio tardio com geminação em grade bem desenvolvida $(M c)$, de muscovita $(M s)$, de quartzo $(Q t z)$ e de fluorita (Fl) em plagioclásio do biotita-granito. NX

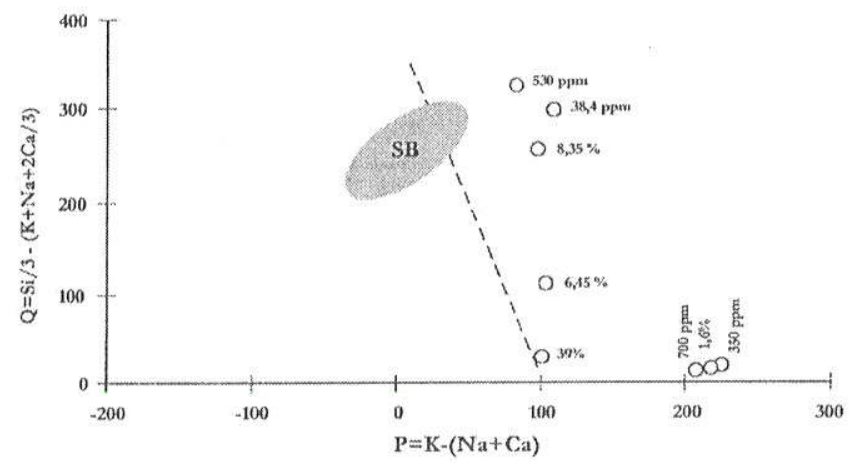

Figura 6 - Diagrama Q-P para os greisens do Maciço Serra Branca. O traço pontilhado reprsenta a repartição dos greisens, de acordo com Charoy (1979). Os números correspondem aos teores em Sn. SB representa o campo de compsoição dos granitos do Maciço Serra Branca.

te durante o fenômeno de greisenização do MGSB (Fig. 8), seja positivamente (introduzidos, como Rb, Ga, Nb, Sn, W, F), seja negativamente (lixiviados, como Ba e Sr). Especificamente para o W, a dispersão observada no gráfico da Figura 8 deve-se, sobretudo, à presença de scheelita em algumas das amostras analisadas. Comportamentos evolutivos semelhantes aqueles encontrados para granitos e greisens do MGSB são igualmente mencionados na literatura especializada (e.g. Hall 1971, Aleksandrov 1977, Bailey 1977, Charoy 1979, Plimer 1987, Breiter et al. 1991, Cuney et al. 1994). 


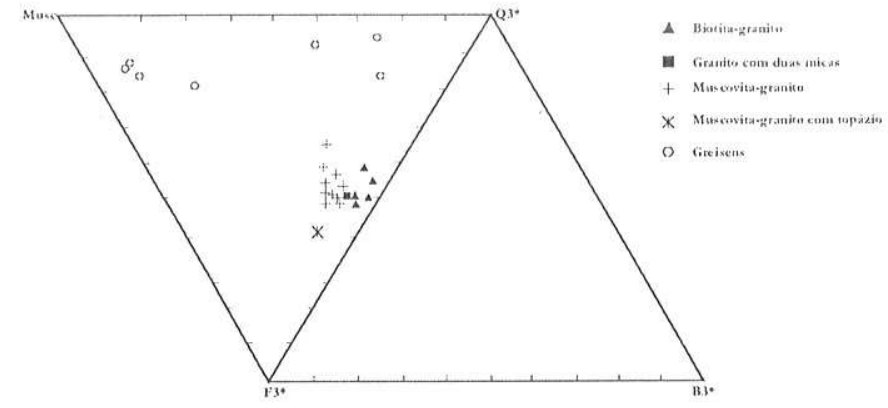

Figura 7-Diagrama Q3*-B3*-F3*(La Roche, 1980) para as fácies graníticas e greisens do Maciço da Serra Branca. Q3 $=\mathrm{Si}+7 \mathrm{Al} / 2-9 \mathrm{Ca}-13(\mathrm{Na}+\mathrm{K}) /$ $2 ; B 3=\mathrm{Si}-7 \mathrm{Al} / 2+7 \mathrm{Ca}+7(\mathrm{Na}+\mathrm{K}) / 2+8(\mathrm{Mg}+\mathrm{Fe}+\mathrm{Ti}) / 3 ;$

$\mathrm{F3}=\mathrm{Si}+\mathrm{Al}+3 \mathrm{Ca}+4(\mathrm{Na}+\mathrm{K})-5(\mathrm{Mg}+\mathrm{Fe}+\mathrm{Ti}) / 3 ; \quad \mathrm{S}=\mathrm{Si}+\mathrm{Al}+\mathrm{Ca}+$ $(\mathrm{Na}+\mathrm{K})+(\mathrm{Mg}+\mathrm{Fe}+\mathrm{Ti})$

$\mathrm{Q}^{*}=100 \mathrm{Q} 3 / \mathrm{\Sigma} \quad ; \mathrm{B} 3^{*}=100 \mathrm{~B} 3 / \mathrm{\Sigma} \quad ; \mathrm{F}^{*}=100 \mathrm{~F} 3 / \mathrm{\Sigma}$
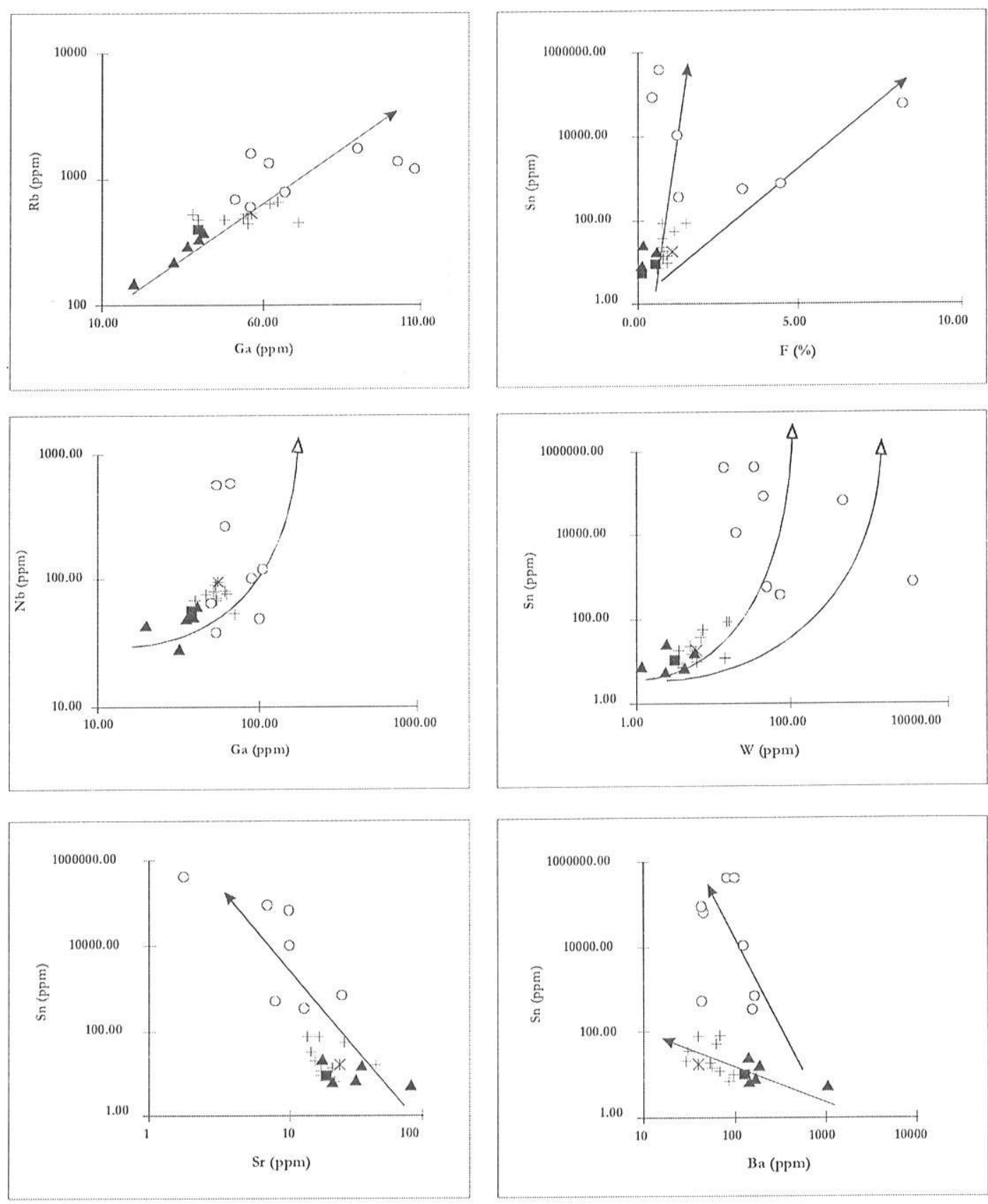

A microclinização é generalizada em todas as fácies, mas tem intensidade (volume) variável. Nos greisens, o microclínio pertítico, com geminação em grade bem desenvolvida e em placas xenomórficas com aspecto límpido, é visivelmente posterior à deformação geral. Apesar de tardiamente cristalizado, uma vez que encontra-se cimentando a cassiterita, pode estar corroído pelo quartzo. Sua composição $\left(\mathrm{Or}_{94}{ }^{-}\right.$ $\mathrm{Ab}$ ) é comparável àquela apresentada pelo microclínio tardio observado nas fácies graníticas do MGSB. Desta maneira, tem-se que o processo de microclinização que atinge as fácies graníticas é um fenômeno de alteração pós-greisenização, tendo se desenvolvido de maneira mais ou menos intensa e, localmente, propiciou a formação de bolsões monominerálicos.

Microclinização tardia é um processo pouco mencionado na literatura. A escola soviética (Scherba 1970) considera que microclinização e albitização tardias podem encontrar-se superimpostas, culminando em fácies apograníticas em cúpulas graníticas. Fonteilles \& Pascal (1985) descrevem uma associação temporal entre uma zona de feldspatização (microclinito, mais raramente albitito) e uma zona de
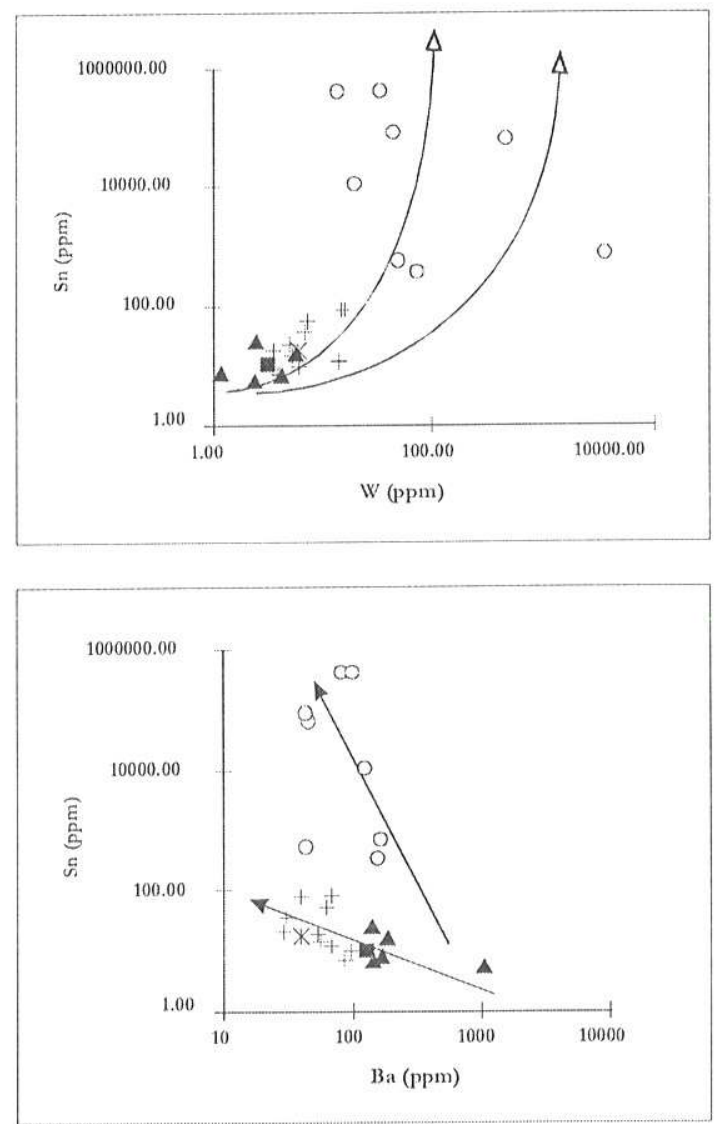

Figura 8 - Reação de distribuição entre Sn e alguns elementos-traços marcadores dos processos de alteração pós-magmáticos nas fáceis graníticas e greisens do Maciço da Serra Branca. 
greisen (muscovita + quartzo), respectivamente, a montante e a jusante de uma coluna metassomática no teto de uma intrusão granítica. De acordo com estes autores, tal processo seria o resultado de variações químicas no fluido que, inicialmente em equilíbrio com os minerais do granito, tornar-se-ia gradualmente mais agressivo durante sua ascensão, com respostas contrastadas (ácido - básico) em função dos gradientes P e T. Charoy \& Pollard (1989) descrevem, igualmente, veios tardios de K-feldspato que seccionam zonas previamente greisenizadas; estes autores não empregam, entretanto, o termo microclinização.

O estabelecimento de uma cronologia dos diferentes processos de alteração pós-magmáticos que afetaram o MGSB conduz à seqüência albitização, greisenização e, em seguida, microclinização. Tal seqüência corresponde apenas parcialmente à cronologia de processos pósmagmáticos estabelecida por Scherba (1970), demonstração da teoria da onda ácida de Korzhinskiy (1958, in Charoy 1979), onde a greisenização representa o máximo da potencialidade da atividade dos compostos ácidos, ou seja, à lixiviação máxima seguem-se os estágios precoces de alteração alcalina.

Esta cronologia de fenômenos pós-magmáticos apresentada pelo MGSB é contrária àquela estabelecida em outros corpos granitóides da Província Estanífera de Goiás (Botelho \& Marini 1984), onde, em geral, a microclinização precede a greisenização.

Agradecimentos Ao Conselho Nacional de Desenvolvimento Científico e Tecnológico - CNPq - pela concessão de bolsa de estudos para a realização do Doutorado da autora, bem como pelo auxílio financeiro liberado para as análises laboratoriais; aos profissionais do SARM/CRPG - França, pelas análises químicas e pelas orientações; aos dois consultores da RBG pela leitura crítica e construtiva do manuscrito; ao Paulo Stolfo, da RWS/KLA, pela ajuda inestimável na recuperação das ilustrações.

\section{Referências}

Aleksandrov I.V. 1977. Geochemistry of Li, Rb and F in granitoid process. Geochemistry International, 14:1-13

Andrade, G. F. de 1978 As mineralizaçōes de estanho, berílio e cobre do granito da Serra Branca, Cavalcante - Goiás. Tese de Mestrado. Universidade de Brasília, 83 p. Bailey J.C. 1977. Fluorine in granitic rocks and melts: a review. Chemical Geology, 19: 1-

Bailey S.W. 1984. Classification and structures of the micas. In Micas, Review in Mineralogy, 13, Washington, Mineralogical Society of America, p. 1-12

Borodina N.S. \& Fershtater G.B. 1988. Composition and nature of muscovites in granites. International Geology Review, 30:375-381

Botelho N.F. 1992. Les ensembles granitiques subalcalins a peralumineux minéralisés en Sn et In de la sous-province Paranã, Etat de Goiás, Brésil. Paris VI, Tese de Doutoramento. 344 p.

Botelho N.F. \& Marini O. 1984. Petrografia, petroquímica e transformações tardi/pósmagmáticas do granito estanífero da Pedra Branca (Goiás). In: SBG, Congresso Brasileiro Geologia, 33, Rio de Janeiro, Anais, 2935-2949

Breiter K., Sokolová M., Sokol A. 1991. Geochemical specialization of the tin-bearing granitoid massifs of NW Bohemia. Mineralium Deposita, 26:298-306

Charoy, B. 1979. Définition et importance des phénomènes deutériques et des fluides associés dans les granites. Conséquences métallogéniques. Tese de Doutoramento, INPL. 277 p.

Charoy B. \& Pollard P.J. 1989. Albite-rich, silica depleted metasomatic rocks at Emuford, Northeast Queensland. Mineralogical, geochemical, and fluid inclusion constraints on hydrothermal evolution and tin mineralization. Economic Geology: 84:1850-1874

Cuney M.. Stussi J.M., Marignac C. 1994. A geochemical comparison between West- and Central-European granites: implications for the origin of rare metal mineralization. In: Metallogeny of collisional orogens. Proceedings of the IAGOD Erzgebirge Meeting. Gever June 4-6, Czech Geological Survey; Praha, 96-102.

Ferry J.M. 1979. Reaction mecanism, physical conditions, and mass transfer during hydrothermal alteration of micas and feldspar in granitic rocks from South-Central Maine, USA. Contributions Mineralogy and Petrology, 68:125-139

Fonteilles M. \& Pascal M.L. 1985. Greisens, veines à quartz muscovite et zones feldspathisées comme éléments d'une même colonne métasomatique. Compté Rendu de l'Académie des Sciences de Paris, série II, 300:755-758.

Hall A. 1971. Greisenization in the granite of Cligga Head, Cornwall. Proc. Geol. Assoc 82:209-230

La Roche H. 1980. Granite's chemistry through multicationic diagrams. Sci. Terre, Informat. Géol. 13:65-88
Manning D.A.C. \& Exley C.S. 1984. The origins of late-stage rocks in the St. Austell granite- a re-interpretation. Journal of Geological Society of London, 141:581-591 Marini,O.J. \& Botelho N.F. 1986. A Província Estanífera de Goiás. Revista Brasileira de Geociências, $22: 8-19$

Miller C. F., Stoddard E.F., Bradfish L.J., Dollase W. A. 1981. Composition of plutonic muscovite: genetic implications. Canadian Mineralogist, 19: 25-34

Moore D:E. \& Liou J.G. 1979. Chessboard-twinned albite from Franciscan metaconglomerates of the Diablo Range, California. American Mineralogist, 64:329336

Orville P.M. 1963. Alkali-ion exchange between vapour and feldspar phases. American Joumal of Sciences, 261:201-237

Pascal M.L. 1979. Les albitites du Massif de l'Agly (Pyrénées Orientales). Tese de Doutoramento. Paris. $157 \mathrm{p}$.

Pichavant M. 1983. (Na,K) exchange between alkali-feldspars and aqueous solutions containing borates and fluoride anions. Experimental results at I Kbar. In: 3Rd NATO Advanced Study Institute on feldspars. Rennes: 102.

Pinto-Coelho C. 1996. Evolution magmatique et hydrothermale du Massif granitique de Serra Branca - Etat de Goiás - Brésil: définition des processus d'altération postmagmatique en liaison avec les minéralisations en Sn, Be et F. INPL. Tese de Doutoramento. 271 p.

Pinto-Coelho C., Botelho N.F., Roger G. 1999. Mobilité des terres rares au cours des altérations hydrothermales: l'exemple du granite de Serra Branca- Brésil Central. C.R. Acad. Sci. Paris 328, 663-670

Plimer I.R. 1987. Fundamental parameters for the formation of granite-related tin deposits. Geol. Rundsch. 76:23-40

Pollard P.J., Pichavant M., Charoy B. 1987. Contrasting evolution of fluorine-and- boronrich tin systems. Mineralium Deposita, 22: 315-321

Scherba G.N. 1970. Greisens. International Geology Review, 12:(2)114-150, (3)239-255 Smith J.V. 1974. Feldspar Minerals. Spring Verlag, Berlin.

Speer J.A. 1984. Micas in igneous rocks. In Micas, Review in Mineralogy, 13, Washington, Mineralogical Society of America, p. 299-356

Stemprok M. 1987. Greisenization (a review). Geol. Rundsch. 76: 169-175.

Witt W.K. 1988. Evolution of high-temperature hydrothermal fluids associated with greisenization and feldspathic alteration of a tin-mineralized granite, Northeast Queensland. Economic Geology', 83:310-334

Manuscrito A-1083

Recebido em 30 de marco de 1999 Revisão dos autores em 30 de março de 2000 Revisão aceita em 10 de setembro de 2000 